\title{
The Nature of Self-Inhibition of Germination of Conidia of Glomerella cingulata
}

\author{
By B. T. LINGAPPA AND YAMUNA LINGAPPA \\ Holy Cross College, Worcester, Massachusetts, U.S.A.
}

(Received 4 October 1965)

\begin{abstract}
SUMMARY
Conidia of Glomerella cingulata did not germinate under crowded conditions. This was not due to limiting effects of concentration of oxygen or carbon dioxide. The ill effect of crowding on germination was alleviated by adding large amounts of twice-crystallized bovine serum albumin. Nearly $88 \%$ conidia germinated in redistilled water when they were present in amounts less than $100 / \mathrm{mm}^{2}$; but on addition of the washings and exudates of conidia into such suspensions, germination as well as length of germ tubes was markedly decreased. Germination of conidia was increased by prolonged leaching of the conidia by soaking in redistilled water. More than $\mathbf{3 0} \%$ of the thoroughly leached conidia germinated in redistilled water under crowded conditions $\left(3000 / \mathrm{mm}^{2}\right)$, whereas less than $2 \%$ of the conidia sampled before leaching germinated under similar conditions. It is concluded that diffusible inhibitory compounds from the conidia appear to be responsible for the inhibition of germination. Several solubility classes of inhibitory compounds have been extracted from the cultures of $G$. cingulata. Among them, a basic fraction was relatively more toxic to G. cingulata than to Bacillus subtilis.
\end{abstract}

\section{INTRODUCTION}

The percentage germination of conidia of Glomerella cingulata has been found inversely proportional to concentration of conidia (Lingappa \& Lingappa, 1965). Washed conidia do not germinate on laboratory media when dispersed in amounts greater than $3000 / \mathrm{mm}^{2}$, but they do germinate readily in redistilled water when there are less than 100 conidia $/ \mathrm{mm}^{2}{ }^{2}$ It follows that the conidia are not nutritionally deficient. Nevertheless, addition of large amounts of certain nutrients resulted in germination of crowded conidia. Oxygen or carbon-dioxide concentration did not limit germination under those conditions. Studies on the nutrient requirements for germination of conidia of $G$. cingulata suggested that inhibitory metabolites from the conidia, rather than lack of nutrients, might be responsible for the inhibition of germination of crowded conidia. This possibility has been further examined in the present paper.

\section{METHODS}

The cultivation and germination procedures were the same as mentioned previously (Lingappa \& Lingappa, 1965); the concentration of sucrose in the potato sucrose medium was $5 \cdot 6 \%(w / v)$, not $8 \cdot 5 \%(w / v)$ as there reported. For germination studies, conidia from culture slopes were washed three times by suspension in 
water and centrifugation. Serial dilutions of washed conidia were dispensed in $1.5 \mathrm{ml}$. quantities into $35 \times 10 \mathrm{~mm}$. Petri dishes. The conidia settled quickly on the bottom of the Petri dishes. Therefore the concentrations of conidia were expressed in numbers per mm. ${ }^{2}$ The dilutions gave $30-3000$ conidia $/ \mathrm{mm} .{ }^{2}$ The watery supernatant fluid obtained after initial and subsequent washing of conidia was passed through a sterilizing membrane filter in a micro-syringe holder (Millipore Filter Corporation, Bedford, Mass.). Conidia were produced in shaken liquid cultures which were set up by inoculating $10 \mathrm{ml}$. inoculum of about $1.6 \times 10^{8}$ conidia $/ \mathrm{ml}$. into $150 \mathrm{ml}$. medium in $500 \mathrm{ml}$. Erlenmeyer flasks. Cultures were pooled in a large container, passed through a layer of cheesecloth to separate any mycelial balls, and duplicate samples taken to count and to determine the dry weight of conidia. The conidia were separated by centrifugation in an International Refrigerated Centrifuge at $10,000 \mathrm{rev} . / \mathrm{min}$. for $20 \mathrm{~min}$. The separated conidia were washed once. The mycelia, conidia, and media were made acid or alkaline by addition of $\mathrm{N}-\mathrm{HCl}$ or $\mathrm{N}-\mathrm{Na}_{2} \mathrm{CO}_{3}$ and extracted in batches with reagent grade chloroform or dichloromethane (Fig. 2). The extracts were uniformly evaporated to dryness over filterpaper assay discs in a Flash-Evaporator (Buchler Instrument Inc., Fort Lee, New Jersey), at $40^{\circ}$, and at $0-20 \mathrm{~mm}$. $\mathrm{Hg}$ pressure.

The biological activity of these extracts was tested as follows (Skinner, 1955): Half-strength potato sucrose medium, with $1.8 \%$ agar, was melted and cooled to $42^{\circ}$. The test organisms, which included conidia of Glomerella cingulata $\left(10^{6} / \mathrm{ml}\right.$.) and endospores of Bacillus subtilis $\left(10^{7} / \mathrm{ml}\right.$.), were uniformly suspended in agar and poured into Petri dishes, $12 \mathrm{ml}$. into $10 \mathrm{~cm}$. diam. Petri dishes, or $20 \mathrm{ml}$. into $15 \mathrm{~cm}$. diam. dishes. On these solidified seeded agar plates, assay discs containing the evaporated extracts were placed. Solvent control discs, containing the solvents or the residues left by evaporating amounts of solvents equal to the amounts used for extraction or fractionation, were also included in the assays. Because acids and alkalis used in adjusting the $\mathrm{pH}$ value of cultures give zones of inhibition, solvent extracts were carefully separated to avoid carry-over of emulsions. After incubation for $16 \mathrm{hr}$ at $25^{\circ}$, the diameters of clear inhibition zones surrounding the assay discs were measured and recorded. Assay discs containing equal amounts of any one extract or fraction were assayed. In this way the activity of any one extract, or of a fraction, on $G$. cingulata could be compared with the corresponding activity on B. subtilis.

Extracts obtained from $\mathrm{CHCl}_{3}$ or $\mathrm{CH}_{2} \mathrm{Cl}_{2}$ were further separated into five fractions solubility classes by following the procedure for separation of mixtures of waterinsoluble compounds outlined by Shriner, Fuson \& Curtin (1956; Fig. 3). These fractions were again assayed against test organisms. Preliminary chemical studies on these fractions were made following Shriner et al. (1956) and Openshaw (1955).

\section{RESULTS}

\section{Effect of crystalline bovine albumin}

Albumins inactivate many antimicrobial agents by binding, and therefore 4-9\% serum albumin is included in antibiotic assays (Kavanagh \& Dennin, 1963). Twice-crystallized bovine albumin (Nutritional Biochemical Corp., Cleveland, Ohio) was added to conidial suspensions to test whether the self-inhibitory metabolites of the conidia 
were inactivated. Addition of albumin increased the germination of conidia in all conidial concentrations tested (Table 1). The effect of albumin was similar to that of Bactopeptone (Difco Laboratories, Detroit, Michigan). Peptone, however, was 3-5 times more effective on a weight basis than albumin in counteracting the inhibitory effects of crowding of conidia (Table 2). Soluble starch (B and A, Allied Chemical, New York, reagent grade) showed no effect at from 1 to $4 \mathrm{mg}$./dish.

Table 1. Effect of bovine albumin, $25 \mathrm{mg} . / \mathrm{dish}$, on germination of conidia of Glomerella cingulata

$\begin{array}{ccc}\begin{array}{c}\text { No. } \\ \text { conidia/mm. }\end{array} & \overbrace{\text { In water }}^{\text {Germination (\%) }} \\ 30 & 84 & \begin{array}{c}\text { In } \\ \text { albumin }\end{array} \\ 60 & 64 & 93 \\ 120 & 39 & 86 \\ 220 & 19 & 80 \\ 400 & 10 & 64 \\ 950 & 4 & 37 \\ 1700 & 3 & 22 \\ 3100 & 1 & 14 \\ & & 10\end{array}$

Table 2. Effect of albumin and of peptone on crowded conidia $\left(3000 / \mathrm{mm}^{2}\right)$ of Glomerella cingulata

\begin{tabular}{|c|c|}
\hline \multicolumn{2}{|c|}{ Bovine albumin } \\
\hline mg./dish & $\begin{array}{c}\text { Germination } \\
(\%)\end{array}$ \\
\hline o & 1 (control \\
\hline 5 & 2 \\
\hline 10 & 12 \\
\hline 20 & 25 \\
\hline 40 & 56 \\
\hline 80 & 87 \\
\hline
\end{tabular}

\begin{tabular}{|c|c|}
\hline \multicolumn{2}{|c|}{ Bactopeptone } \\
\hline mg./dish & $\begin{array}{c}\text { Germination } \\
(\%)\end{array}$ \\
\hline 1 & 5 \\
\hline 2 & 15 \\
\hline 4 & 32 \\
\hline 8 & 57 \\
\hline 16 & 78 \\
\hline 32 & 95 \\
\hline
\end{tabular}

Effect of exudates of conidia on the germination

Conidia grown at $27^{\circ}$ on agar slopes were densely suspended in water to read a turbidity value of 1 at $400 \mathrm{~m} \mu$. This suspension was centrifuged and the supernatant fluid separated. The washed conidia were resuspended in water and the process was quickly repeated to obtain second and third washings. The cleaned conidia were suspended in half the original volume of water, to double the concentration of conidia, and designated double-strength suspension. This suspension was incubated in a $15 \mathrm{~cm}$. Petri dish for $4 \frac{1}{2} \mathrm{hr}$ at $27^{\circ}$ and then centrifuged. The supernatant fluid (SE) contained all the materials which had diffused from the conidia. The washed conidia, so obtained, were diluted to $3000 / \mathrm{mm}^{2}$ and allowed to germinate. These thoroughly leached conidia gave $30 \%$ germination in water, whereas corresponding samples taken from the same lot after the first wash gave only $2 \%$ germination.

The watery supernatant fluid from 1st, 2nd, 3rd washings and SE contained 960, 260,60 and $80 \mu \mathrm{g}$. dry matter $/ \mathrm{ml}$., respectively. These fractions were autoclaved or passed through a sterilizing membrane filter and 0.05-1.6 ml. of solution added 
to dishes containing $1.5 \mathrm{ml}$. dilute suspension of conidia; corresponding amounts of water or of $0.5 \%(w / v)$ peptone solution were added to control dishes. These dishes contained about 30 conidia $/ \mathrm{mm}^{2}$ Addition of water alone did not affect germination of conidia (78-82\%), any more than $0.4 \mathrm{ml}$. peptone (2 mg.) solution increased germination and the addition of SE decreased germination (Fig. 1). Autoclaved SE and SE from double-strength suspensions of conidia were more toxic than SE from single-strength suspensions. The 1st, 2 nd and 3rd washings contained small amounts of the medium carried over along with the readily extractable materials of the

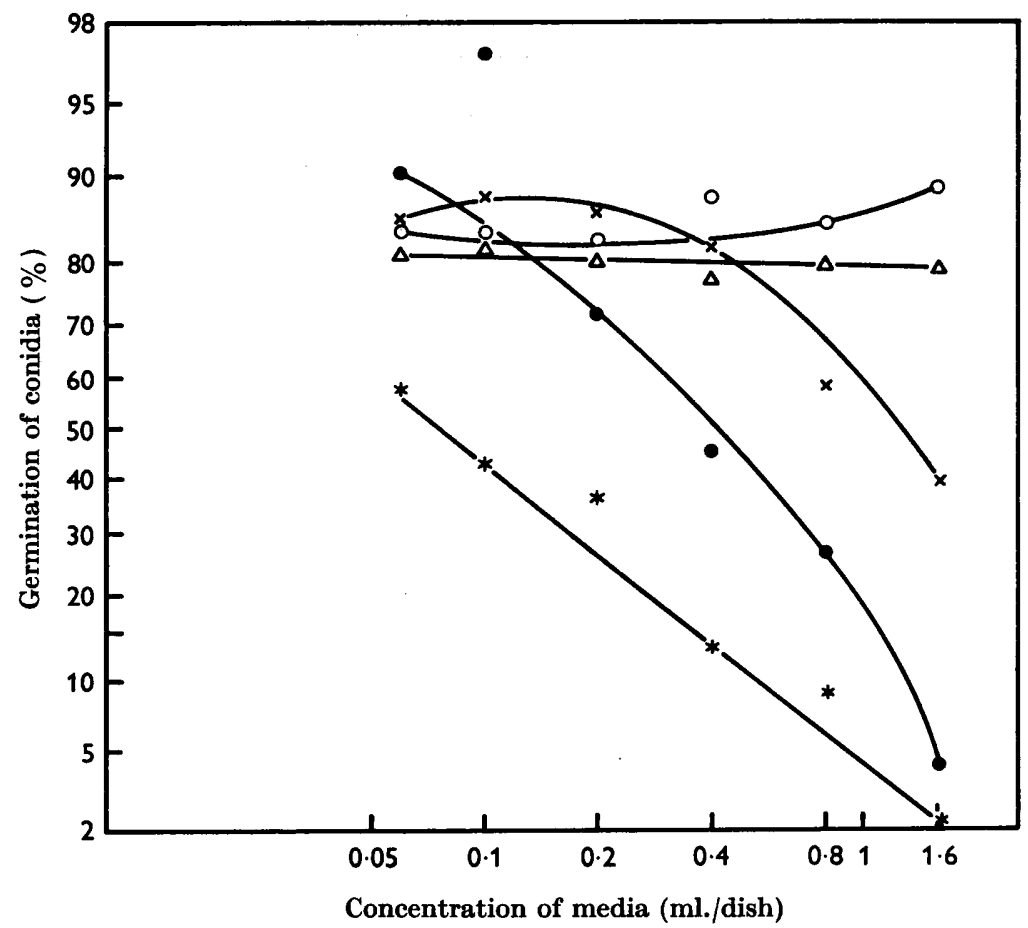

Fig. 1. Effect of adding exudates from conidia of Glomerella cingulata on the germination of conidia of $G$. cingulata. $\triangle \longrightarrow \triangle$, water; $\bigcirc-O$, peptone; $\times \longrightarrow \times$, exudates from single-strength suspension of conidia; - - exudates from double-strength suspensions of conidia; *__ , autoclaved exudates from double-strength suspensions of conidia.

conidia. Addition of more than $0.8 \mathrm{ml} . /$ dish of the washings into dishes containing washed conidia (30/mm. $\left.{ }^{2}\right)$ resulted in $48-53 \%$ germination as compared to $88 \%$ in water, whereas less than $20 \%$ conidia germinated when exudates from conidia (SE) were added. Not only the germination percentage but also the germ-tube length decreased on addition of SE (Table 3).

Conidial exudates were further examined; chloroform extracts were made of $\mathbf{4 5}$ ml. of SE after first adjusting to $\mathrm{pH} 10$ and then to $\mathrm{pH} 4$, and after these extractions the SE was adjusted to $\mathrm{pH} 7$. These preparations were evaporated on filter-paper assay discs and placed on seeded agar plates. After incubation for $16 \mathrm{hr}$ the diameters of zones of inhibition were recorded (Table 4). As compared to other fractions, 
the chloroform extract of SE at $\mathrm{pH} 10$ (SEC pH 10) was the most inhibitory, although other fractions also gave smaller zones of inhibition on Glomerella cingulata. The acidic fraction was more toxic to Bacillus subtilis.

Table 3. Effect of exudates of conidia (SE) on germination and germ-tube growth of conidia (30/mm. $\left.{ }^{2}\right)$ of Glomerella cingulata

$\begin{array}{lcc}\begin{array}{c}\text { Treatment } \\ \text { (ml./dish) }\end{array} & \begin{array}{c}\text { Germination } \\ (\%)\end{array} & \begin{array}{c}\text { Germ-tube } \\ \text { length }(\mu)\end{array} \\ \text { 0.5 water } & 88 & 68 \\ \text { 0.5 Peptone (2.5 mg.) } & 93 & 218 \\ \text { 0.05 SE } & 91 & 167 \\ \text { 0.1 SE } & 97 & 182 \\ \text { 0.2 SE } & 72 & 179 \\ \text { 0.4 SE } & 45 & 90 \\ \text { 0.8 SE } & 27 & 45 \\ \text { 1.2 SE } & 20 & 4\end{array}$

Table 4. Assay of preparations from cultures of Glomerella cingulata

$\begin{array}{lcc}\text { Preparations* } & \begin{array}{c}\text { G. cingulata } \\ \text { Inhibition }\end{array} & \begin{array}{c}\text { B. subtilis } \\ \text { Assay organisms }\end{array} \\ \text { SEC pH 4 } & 7 & 15 \\ \text { SEC pH 10 } & 30 & 15 \\ \text { SE remainder pH 7 } & 12 & 20 \\ \text { MC (solid) pH 4 } & 20 & 25 \\ \text { MC (solid) pH 10 } & 8 & 0 \\ \text { SWC pH 4 } & 7 & 20 \\ \text { SWC pH 10 } & 15 & 25 \\ \text { SC pH 4 } & 20 & 40 \\ \text { SC 1st extract, pH 10 } & 25 & 10 \\ \text { SC 2nd extract, pH 10 } & 15 & 25\end{array}$

* $\mathbf{S E}=$ spore (conidia) exudate, $\mathbf{M}=$ medium, $\mathbf{S W}=$ spore-washings, $\mathbf{S}=$ spores (conidia), $\mathrm{C}=$ chloroform extraction after $\mathrm{pH}$ adjusted to value noted before each preparation.

$\uparrow$ Inhibition zone diameters ( $\mathrm{mm}$.) with 6.85 $\mathrm{mm}$. diam. discs.

\section{Activity of extracts from cultures}

The above data indicated that some conidial-borne metabolites were able to inhibit germination of conidia. To obtain further evidence, direct solvent extraction of the fungus and fractionation of active extracts were attempted. The cultures of Glomerella cingulata were harvested on 3rd, 7th, and 14th days and extracted as shown in Fig. 2. The activities of the various preparations clearly indicated that substances obtained from the cultures which had been adjusted to pH 10 were relatively more toxic to conidia of $G$. cingulata than to endospores of Bacillus subtilis (Table 4). Extracts obtained from acidified preparations were also toxic to conidia but they were more toxic to $B$. subtilis. Obviously these extracts were crude mixtures of compounds belonging to the particular solubility class. Larger zones of inhibition were obtained from older than from younger cultures but those extracted from 7-day conidia gave greater activity than those from 3- or 14-day conidia (Table 5). 
Fractionation and nature of the extract obtained under alkaline conditions

Acid and alkaline dichloromethane extracts were pooled and filtered through analytical filter paper to remove fine particles. The extracts were then dried under vacuum and assayed to make sure that they retained inhibitory activity against Glomerella cingulata. This dried pool was redissolved in dry diethylether, filtered and processed as in Fig. 3. Samples of the five fractions obtained were dried on assay

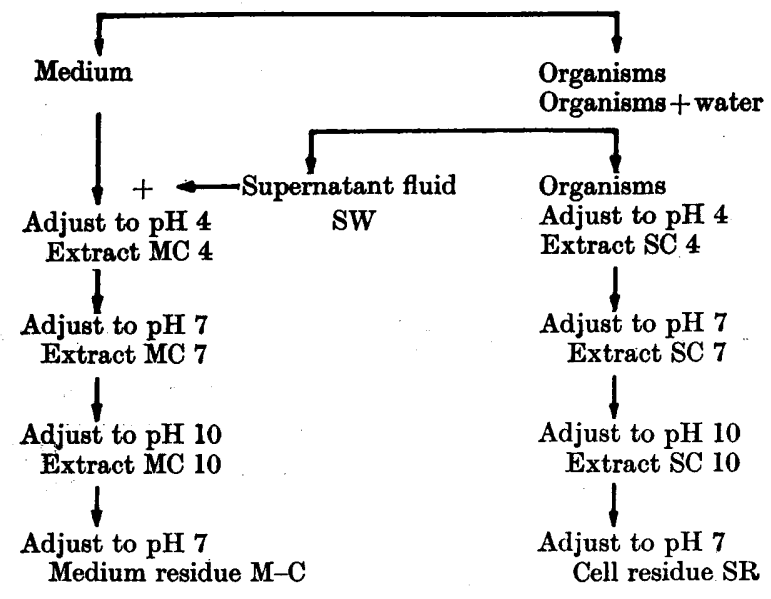

Fig. 2. Cultures of Glomerella cingulata: extraction procedure. pH adjusted with $\mathrm{N}-\mathrm{Na}_{2} \mathrm{CO}_{2}$ or $\mathrm{N}-\mathrm{HCl}$. Extracted by 3 changes of $\mathrm{CHCl}_{3}$ or $\mathrm{CH}_{2} \mathrm{Cl}_{2}$.

Table 5. Activities of preparations from cultures of different ages of Glomerella cingulata

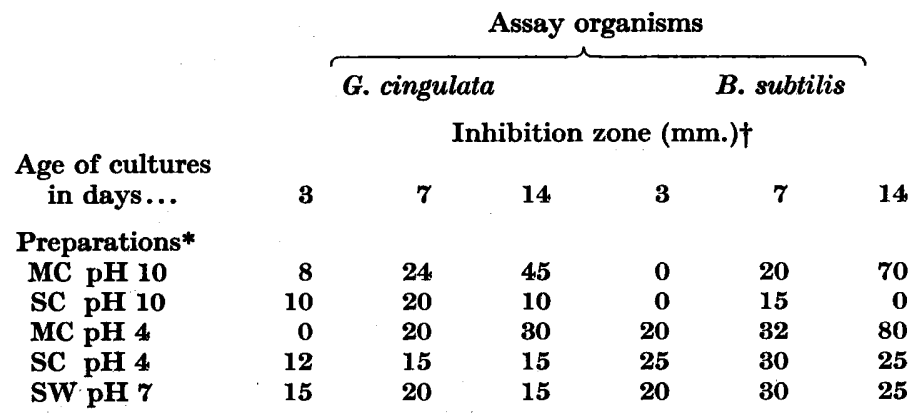

* $\mathrm{MC}=$ chloroform extract of media, $\mathrm{SC}=$ chloroform extract of conidia, $\mathrm{SW}=$ water extract of conidia (obtained by washing 3 times).

$\dagger$ Zone diameters in $\mathrm{mm}$. with $6.35 \mathrm{~mm}$. assay dises.

discs and assayed. The results indicated that all fractions had some inhibitory properties but the basic fraction was significantly more active against $G$. cingulata than against Bacillus subtilis (Table 6). 


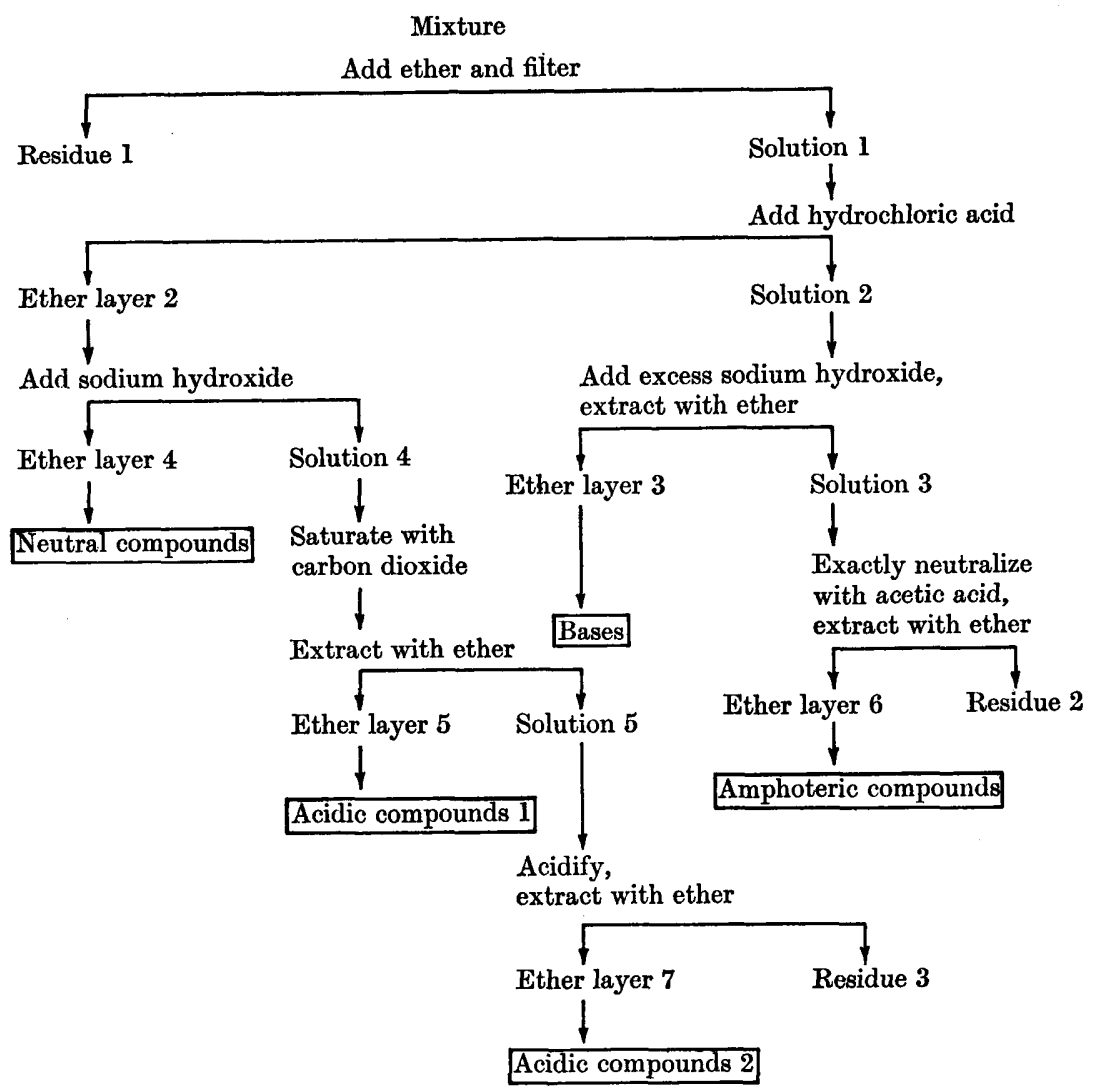

Fig. 3. Germination of conidia of glomerella: fractionation procedure.

\section{Table 6. Activity of fractions of crude dichloromethane extracts of cultures of Glomerella cingulata}

$\begin{array}{lcc}\text { Fraction assayed } & \text { G. cingulata } & \text { B. subtilis } \\ \text { Base } & 25 & 8 \\ \text { Neutral compounds } & 7 & 0 \\ \text { Acidic 1 } & 10 & 25 \\ \text { Acidic 2 } & 20 & 10 \\ \text { Amphoteric } & 15 & 10 \\ \text { * Zone diameter with } \mathbf{3 . 2} \mathrm{mm} \text {. assay dises. }\end{array}$

\section{DISCUSSION}

We found previously that the washed conidia of Glomerella cingulata did not germinate in water under crowded conditions $\left(3000 / \mathrm{mm}^{2}\right.$; Lingappa \& Lingappa, 1965). Germination of crowded conidia was not increased by aeration but by the addition of peptone, or of amino acids. This ruled out the concentration of oxygen or of carbon dioxide as a limiting factor, and indicated that there was a need for exogenous supply of nutrients for germination of crowded conidia. Nevertheless, 
the conidia germinated readily in redistilled water when dispersed in amounts less than $100 / \mathrm{mm}^{2}$. It was, then, suggested that the stimulatory compounds might be binding and inactivating some self-inhibitory metabolites of the conidia. This has now been further supported by the stimulatory effect of twice-crystallized bovine albumin on germination of conidia (Tables 1 and 2). High-percentage germination was obtained with $80 \mathrm{mg}$. albumin per dish, i.e. $4 \%$ albumin (Table 2). This does not give any indication of the nature of the inhibitor because albumins are nonspecific binding agents. Various drugs, antibiotics, lipids and metal ions are bound and inactivated by albumins. Some substances, however, show greater activity in presence of albumin; serum albumin inactivated tyrocidine but the antibiotic activity of gramicidin was enhanced several fold by albumin (Dubos, 1949). The inhibitory effect of triacetin on Candida albicans was enhanced by albumin (Kubista \& Derse, 1959).

Further evidence that diffusible inhibitors of the conidia might be responsible for inhibition of germination of crowded conidia was obtained by washing the conidia. Previously it was shown that washed conidia germinated better than the unwashed ones. At that time, it was not clear whether the repeated washing removed the inhibitors from the conidia or whether the conidia were picking up some contaminating trace elements from successive changes of redistilled water. Acidwashed and thoroughly water-washed Pyrex glass gives out to distilled water $\left(\mu \mathrm{g} . / \mathrm{cm} .{ }^{2} /\right.$ day at $\left.20^{\circ}\right) \mathrm{Si}, 0.02 ; \mathrm{B}, 0.002 ; \mathrm{Al}, 0.0002 ; \mathrm{Na}, 0.0005 ; \mathrm{K}, 0.00001$; and other elements, 0.00001 (data supplied by the manufacturer, Corning Glass Works, Corning, N.Y.). Therefore, instead of using many separate changes of redistilled water, the conidia were leached by soaking for $4 \frac{1}{2} \mathrm{hr}$ and the supernatant fluid (SE) added to sparsely dispersed conidia $\left(30 / \mathrm{mm}^{2}\right)$. Addition of such exudates of conidia (SE) not only decreased the germination of conidia but also decreased the length of the germ tubes (Fig. 1; Table 3). In other words, the crowding effect could be reproduced for sparsely dispersed conidia by adding diffusates from dense suspensions of conidia. It follows that the washings contained some inhibitory substances leached from the conidia. Furthermore, $30 \%$ of the leached conidia germinated when dispersed at $3000 / \mathrm{mm}^{2}$ in redistilled water as compared to $2 \%$ germination of unsoaked conidia. These results confirmed that the removal of diffusible inhibitors from the conidia enabled them to germinate under crowded conditions.

Extracts from conidia of Glomerella cingulata were also assayed on endospores of Bacillus subtilis to differentiate general antimicrobial components from selfinhibitors. Any product of an organism which is inhibitory to the organism producing it is considered to be a self-inhibitor. However, a self-inhibitor may or may not have other antibiotic properties. Fractions were obtained from $G$. cingulata some of which were more toxic to itself than to B. subtilis (Tables 4-6). More precise classification of these products into self-inhibitor or antibiotic will be possible only after purifying the compounds because the activities of crude extracts are not comparable on the basis of weight.

No attempt was made to identify the different fractions chemically. The chloroform extracts of acidified cells and media were tentatively identified as lipids, since glycerides, fatty acids, phospholipids and sulpholipids have been found in the lipids of conidia of Glomerella cingulata (Jack, 1964 $a, b$ ). Self-inhibitory substances resembling short-chain fatty acids or their derivatives have been obtained from the 
uredospores of Uromyces phaseoli, whose germination is also diminished by crowding (Bell \& Daly, 1964). Fatty acids and their derivatives have antimicrobial effects (Scholefield, 1963). Spores of fungi are rich in reserve lipids which are actively utilized by the spores (Shu, Tanner \& Ledingham, 1954; Lingappa \& Sussman, 1959; Gottlieb, 1964). Some fatty acids are stimulatory to the spores (Farkas \& Ledingham, 1959) while others are inhibitory (Lewis \& Johnson, 1964). Triacetin, a neutral lipid, is as fungitoxic to Candida albicans as nystatin (Kubista \& Derse, 1959). Triacetin, $10 \mathrm{mg}$./assay disc measuring $3.5 \mathrm{~mm}$. diam., gave zones of inhibition $10 \mathrm{~mm}$. diameter on both G. cingulata and Bacillus subtilis; tripalmitin was non-toxic to both organisms. Germination of spores of several bacteria is inhibited by rancid products of fats (Roth \& Halvorson, 1952); these are so toxic that the inhibition of germination of spores of $B$. subtilis was proposed as a sensitive measure of rancidity of fats (Ramsey \& Kemp, 1963). Chlorellin, a self-inhibitor of Chlorella vulgaris, was identified as a breakdown product of lipids (Spoehr et al. 1949; Scutt, 1964). Our results indicated that in comparable amounts the lipid fractions were relatively more toxic to $B$. subtilis than to G. cingulata (Tables 4 and 6), whereas the basic fraction was more toxic to $G$. cingulata than to $B$. subtilis. The selectively inhibitory basic fraction is the first such self-inhibitor reported in fungi. Occurrence of self-inhibitory metabolites and cellular constituents is clearly demonstrated in $G$. cingulata by these findings. The actual role of any combination of these inhibitors in the living organism is open to future studies.

The existence of self-inhibitors was known in fungi (Sussman, 1965; Cochrane, 1958). Recently, self-inhibitory products have been demonstrated in several fungi (Carlile \& Sellin, 1963; Lingappa \& Lingappa, 1964). Rotem (1963) found evidence for the existence of water-soluble, non-diffusible, and heat-labile self-inhibitors in the mycelium of Alternaria pori f. sp. solani. The mycelium of Psilocybe paneoliformis was reported to contain inhibitors which prevent fruiting (Urayama, 1960). Staling product in the cultures of several fungi grown in presence of 2,4-D and other phenoxy compounds has the attribute of a self-inhibitor (Naito, 1958). None of these self-inhibitors have been characterized. Until then the actual role of these compounds in the regular development and function of the organisms producing them will remain uncertain. It is inconceivable how self-inhibitors, if any are produced, can be without any regulatory function in the organism producing them. Self-inhibition of germination due to crowding might be of considerable survival value to the organism, preventing germination until well dispersed on suitable hosts or nutrient substrates.

This work was supported by research grants from the U.S. National Science Foundation, GB-645 and GB-3179. We are grateful to Prof. K. V. Thimann for criticism and advice and to Dr G. R. Mandels and Prof. A. S. Sussman for generous help. 


\section{REFERENCES}

Bell, A. A. \& Daly, J. M. (1962). Assay and partial purification of self-inhibitors of germination from uredospores of the bean rust fungus. Phytopathology, 52, 261.

Brian, P. W. (1957). The ecological significance of antibiotic production. In Microbial Ecology, Symp. Soc. gen. Microbiol. 7, 168.

Carline, M. J. \& Sellin, M. A. (1963). An endogenous inhibition of spore germination in fungi. Trans. Br. mycol. Soc. 46, 15.

Cochrane, V. W. (1958). Physiology of Fungi. New York: John Wiley.

Crocker, W. (1948). Growth of Plants. New York: Reinhold.

Dubos, R. J. (1949). Tyrothricin and Gramicidin. In Antibiotics. Brooklyn, N.Y.: Chemical Publishing Co. Inc.

Farkas, G. L. \& Ledingham, G. A. (1959). The relation of self-inhibition of germination to the oxidative metabolism of stem rust uredospores. Can. J. Microbiol. 5, 141.

GotTlieb, D. (1964). Germination of fungus spores. Endeavour, 23, 85.

JACK, R. C. M. (1964a). Lipid metabolism in fungi. I. Lipids of the conidia of Glomerella cingulata. Contrib. Boyce Thompson Inst. 22, 311.

JACK, R. C. M. (1964, b). Lipid metabolism in fungi. II. Characterization of conidial lipids of Glomerella cingulata by infrared solution spectra. Contrib. Boyce Thompson Inst. 22, 335.

Kavanagh, F. \& Dennin, L. J. (1963). Penicillins. In Analytical Microbiology. New York and London: Academic Press.

Kubista, R. A. \& Derse, P. H. (1959). A comparison of triacetin and nystatin with respect to their stability and effect on Candida albicans. Antibiotics Chemother. 9, 546.

LEwis, H. L. \& Johnson, G. T. (1964). Growth and oxygen uptake responses of Cunninghamella echinulata on even-chain fatty acids. (Abstract.) Am. J. Bot. 51, 679.

Lingappa, B. T. \& Lingappa, Y. (1964). Self-inhibitory products of fungi. Bact. Proc. p. 35.

LINGAPPA, B. T. \& LINGAPPA, Y. (1965). Effects of nutrients on self-inhibition of germination of conidia of Glomerella cingulata. J. gen. Microbiol. 41, 67.

Lingappa, B. T. \& Sussman, A. S. (1959). Endogenous substrates of dormant, activated and germinating ascospores of Neurospora tetrasperma. Plant Physiol. 34, 466.

Natro, N. (1958). Production of fungitoxic substance by fungi grown on media containing either 2,4-D or related phenoxy compounds. Jap. J. Bot. 16, 153.

Openshaw, H. T. (1955). A Laboratory Manual of Qualitative Organic Analysis, 3rd ed. Cambridge: University Press.

RAMSAY, C. B. \& KEMP, J. D. (1963). Inhibiting action of oxidized pork fat on the germination of spores of Bacillus subtilis. J. Fd Sci. 28, 562.

Rotem, J. (1963). Inhibition of germination of spores of Alternaria pori f. sp. solani. Phytopathology, 53, 1241.

Rotr, N. G. \& Halvorson, H. O. (1952). The effect of oxidative rancidity in unsaturated fatty acids on the germination of bacterial spores. J. Bact. 63, 429 .

Scholefield, P. G. (1963). Fatty acids and their analogues. In Metabolic Inhibitors, vol. 1., p. 153. New York: Academic Press.

Scurt, J. E. (1964). Autoinhibitor production by Chlorella vulgaris. Am. J. Bot. 51, 581.

Shriner, R. L., Fuson, R. C. \& Curtin, D. Y. (1956). The Systematic Identification of Organic Compounds. A laboratory manual, 4th ed. New York: John Wiley.

Shu, P., Tanner, K. G. \& Ledingham, G. A. (1954). Studies on the respiration of resting and germinating uredospores of wheat stem rust. Can. J. Bot. 32, 16.

Skinner, F. A. (1955). Antibiotics. In Modern Methods of Plant Analysis, vol. 3., p. 626. Berlin: Springer-Verlag.

Spoehr, H. A., Smith, J. H. C., Strain, H. H., Milner, H. W. \& Hardin, G. J. (1949). Fatty acid antibacterials from plants. Publs Carnegie Instn no. 586.

Sussman, A.S. (1965). Physiology of dormancy and germination in the propagules of cryptogamic plants. In Encyclopedia of Plant Physiology, vol. 15., p. 933. Berlin: SpringerVerlag.

Urayama, T. (1960). Studies on fruit body formation of Psilocybe paneoliformis Murrill in pure culture. Mem. Fac. lib. Arts Educ. Miyazaki Univ. 9, 393.

WoodruFr, H. B. (1961). Antibiotic production as an expression of environment. In Microbial Reaction to Environment. Symp. Soc. gen. Microbiol. 11, 317. 